\title{
CD91-Dependent Modulation of Immune Responses by Heat Shock Proteins: A Role in Autoimmunity
}

\author{
Robert J. Binder, Yu Jerry Zhou, Michelle N. Messmer, and Sudesh Pawaria \\ Department of Immunology, University of Pittsburgh, 200 Lothrop Street, Pittsburgh, PA 15261, USA \\ Correspondence should be addressed to Robert J. Binder, rjb42@pitt.edu
}

Received 15 June 2012; Accepted 15 October 2012

Academic Editor: Kamal D. Moudgil

Copyright ( $) 2012$ Robert J. Binder et al. This is an open access article distributed under the Creative Commons Attribution License, which permits unrestricted use, distribution, and reproduction in any medium, provided the original work is properly cited.

\begin{abstract}
Heat shock proteins (HSPs) have been known for decades for their ability to protect cells under stressful conditions. In the 1980s a new role was ascribed for several HSPs given their ability to elicit specific immune responses in the setting of cancer and infectious disease. These immune responses have primarily been harnessed for the immunotherapy of cancer in the clinical setting. However, because of the ability of HSPs to prime diverse immune responses, they have also been used for modulation of immune responses during autoimmunity. The apparent dichotomy of immune responses elicited by HSPs is discussed here on a molecular and cellular level. The potential clinical application of HSP-mediated immune responses for therapy of autoimmune diseases is reviewed.
\end{abstract}

\section{Introduction: HSPs in Immunity}

Expression of HSPs is generally upregulated in cells in response to a variety of stressful conditions including nonphysiological temperature, nutrient deprivation, and hypoxia [1]. It is the inherent chaperoning function of HSPs that allows them to provide their cytoprotective function in assisting correct protein/polypeptide folding and preventing further protein denaturation. It has become evident over the past two decades that the chaperoning function of HSPs also plays a key role in several processes during the development of immune responses [2]. Within the cell, several HSPs act as chaperones of peptides that are ultimately presented by MHC I and MHC II molecules. Thus, the HSPs in the cytosol and in the endoplasmic reticulum form a relay line for the transport of peptides from their formation by the proteasome to the MHC I heavy chain (HC). This is discussed in the next subheading. As the HSPs are some of the most abundant proteins in cells, their liberation into the extracellular environment has been shown to be a key indicator of loss of cellular integrity and they are rapidly recognized by the cellular sentinels of the immune system. Such recognition allows for cross-priming of the potential antigens that the HSPs chaperone. The efficiency of this pathway predicted a cell surface receptor on the cross-presenting cells and that receptor has now been shown to be CD91. These events are discussed in the next two subheadings. The isolation of HSPs (and the associated peptides) from tumor cells or cells infected with pathogens therefore provides a single entity that primes immune responses specific for the chaperoned peptides and thus for the cell that harbored these antigens. This application has been tested in a vast number of rodent models of cancer and infectious disease and is being tested in the clinical setting. We discuss this in the third subheading. A search for optimal immunizing doses of HSPs led to the fortuitous dampening of the immune response at higher doses of HSPs. This phenomenon has been applied to the therapy of autoimmunity and is the focus of the last subheading. This chapter is largely restricted to the HSPs gp96, hsp70, hsp90, and calreticulin although others such as hsp110, grp170 have been shown to elicit similar immune responses $[3,4]$.

\section{HSPs Form a Relay Line in MHC I Antigen Processing and Presentation}

The classical and current view of antigen processing and presentation by MHC I can be summed up as follows: production of peptides occurs within the cytosol by the 
large multi-subunit catalytic body called the proteasome. The proteasome ingests polypeptides and trims them down to small peptides usually with the correct C-termini, but extended N-termini, for MHC I binding. The transporter associated with antigen processing (TAP) pumps peptides into the ER in an ATP-dependent manner. Additional Nterminal trimming proteases such as the ER-associated aminopeptidase (ERAP) are present in the ER for final processing [5]. For a period these peptides were envisioned to diffuse to TAP, and once in the ER, they diffuse and get loaded onto MHC HC with the assistance of the peptide loading complex. We now know that diffusion plays a minor role if any at all in antigen presentation; instead, peptide trafficking is possible only because peptides are actually chaperoned by HSPs. This was first proposed in 1994 [6] and the evidence for the involvement of HSPs in peptide processing and presentation is now abundantly clear and comes in both direct and indirect forms. The evidence is as follows: (i) disruption of peptide binding by HSPs abrogates MHC I peptide presentation [7-9], (ii) the extremely poor efficiency of diffusion of peptides within the cell cannot account for the calculated efficiency of antigen presentation $[10,11]$, unless other more efficient methods of peptide trafficking, such as the HSP chaperoning effect, are integrated into the pathway, (iii) free peptides have not been found in cells even after a careful search for them [12]. The peptides are readily seen once they are released from HSPs by protein denaturation or treatment with ATP or acid [13], (iv) given the hydrophobic residues of amino acids in the hydrophilic environment, solubility issues that this poses [14] must be resolved, and peptide association with HSPs does so, (v) isolation of peptides from highly purified HSP preparations reveals MHC binding peptides and their precursors (intermediates of the processing events) [15-20]; (vi) peptides chaperoned by hsp90 in the cytosol are less processed (longer) than those chaperoned by the ER HSP gp96 revealing a continuum of processing events by proteases in different compartments [15], and (vii) shuttling of MHC binding peptide precursors between HSPs and MHC I HC has been observed in the ER [17]. These lines of experimental evidence suggest and provoke the idea that the relatively recent evolutionary development of the MHC I antigen processing and presentation pathway, a key component of adaptive immunity, has taken advantage of the ancient property of HSP chaperoning.

\section{HSP-Peptide Complexes in Antigen Cross-Presentation}

The initial event in priming T-cell responses to cancer or infectious disease involves the transfer of antigens from the cells that harbor them to antigen presenting cells. This pathway is called cross-presentation and allows for the presentation of antigens in the form of peptides to $\mathrm{T}$ cells in the context of MHC molecules. Cross-presentation of antigens by APCs also directs that the antigen is presented in the context of costimulation, which is a combination of cytokines and a series of APC-T cell interactions through receptors and their corresponding ligands. The specific costimulation received by the naïve $\mathrm{T}$ cell dictates the type of $\mathrm{T}$ cell response that is primed. HSPs have been shown to play a critical role both in cross-presentation of antigens and in provision of a dynamic set of signals for costimulation.

Calculations on the amount of antigen that is available for cross-presentation in two independent studies have shown that it is insufficient if the antigens were transferred as a whole protein $[21,22]$. This triggered an investigation into the role of HSP-antigen complexes as a necessary alternative to antigen transfer during cross-presentation. Antigens chaperoned by HSPs are cross-presented approximately 50,000 times more efficiently than naked protein and/or peptide alone [22]. This increase of efficiency is in large part due to the presence of the HSP receptor CD91 that is present on APCs $[23,24]$. Although the role of HSPs in crosspresentation has been demonstrated in vivo, it has been modeled in vitro in several antigenic systems in mice and humans over a period of many years (Table 1). These studies have shown that the initial interaction of the APC with the HSP is mediated through the cell surface receptor CD91 and potentially others. The evidence, or lack thereof, for these other suggested HSP receptors is discussed elsewhere [25]. Following binding, the HSP with the chaperoned peptide is internalized into endosomal vesicles. Through an as yet unidentified mechanism, peptides are delivered to the cytosol for trimming by the proteasome where they enter the MHC I processing and presentation pathway. Other mechanisms include internalization of HSP-peptide complexes into MHC I containing vesicles where there can be direct peptide transfer between these molecules [2630]. However with this mechanism only fully processed peptides chaperoned by HSPs would be presented by MHC I. The requirement for MHC I antigen processing machinery such as the proteasome and TAP appears to be dependent on the antigenic system being tested $[7,24,31]$. Other mechanisms leading to presentation of peptides chaperoned by HSPs may also be dependent on the HSP chaperoning the antigen, as endogenous and exogenous hsp90 have been shown to be directly involved in transendosomal membrane transport $[32,33]$. Since the peptides bound to HSPs do not appear to be limited by length or amino acid sequence, HSP chaperoned peptides can also be presented by MHC II of the APC to stimulate $\mathrm{CD} 4^{+} \mathrm{T}$ cells [34-37].

By extension of this very efficient mechanism of crosspresentation of HSP-chaperoned antigens, immunization with HSP-antigen complexes primes antigen-specific T-cell responses while comparable amounts of antigen alone does not. This has been demonstrated with gp96 [19, 59-63], hsp90 [15, 62], hsp70 [13, 19, 62], calreticulin $[64,65]$, hsp110 $[3,4]$, and grp170 $[3,4]$. In these immunization regimens, the HSP-peptide complexes can be purified intact from the antigen bearing cell. Thus, purification of HSPs from tumor cells will yield complexes that represent the entire antigenic fingerprint of that tumor and will prime Tcell responses specific for that tumor. The same applies to cells infected with bacteria or viruses and cells expressing minor histocompatibility antigens or model antigens. The peptides bound to HSPs are not restricted to the MHC 


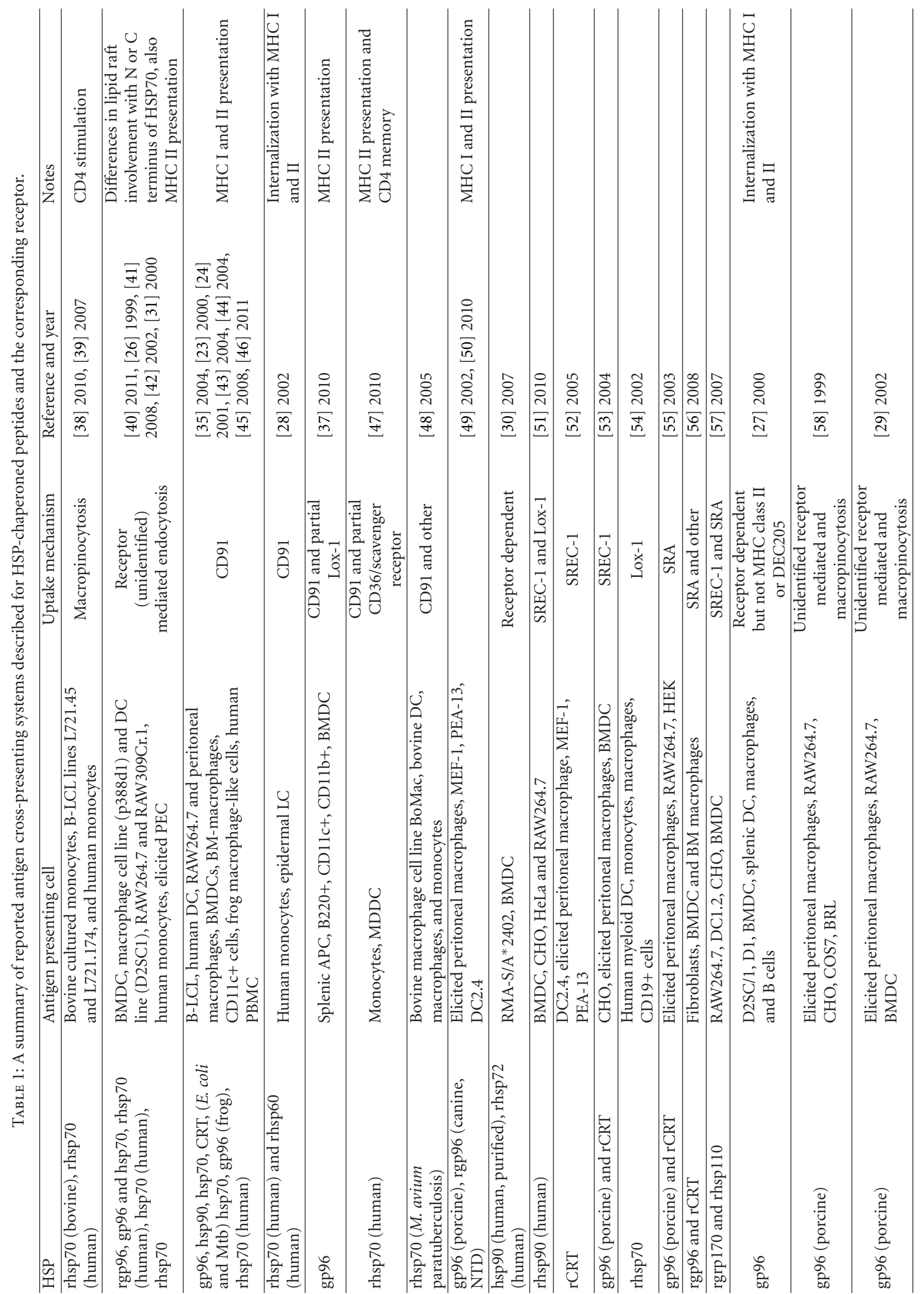


haplotype of the originating cells [66]. Various methodologies are also currently available to artificially bind peptides to HSPs noncovalently [67] or covalently through fusion constructs to form immunogenic complexes [68]. In most cases, the immune response measured after priming is of the Th1 phenotype and characterized by $\mathrm{CD}^{+}$cytotoxic $\mathrm{T}$ lymphocytes. In a few situations, immunization with HSPs has led to priming of Th2/antibody or Th17 responses [69-72].

\section{CD91 Is Pivotal in Regulating HSP-Mediated Costimulation}

HSP-chaperoned peptides can be cross-presented by professional APCs; however, presentation and recognition of antigen alone by $\mathrm{T}$ cells are not sufficient to prime adaptive immunity. In order to prime $\mathrm{T}$ and/or B cells, help is needed from an expanding family of costimulatory molecules on APCs. The cytokine milieu provides additional signals for activation and expansion of these effector cells. The immunogenic HSPs were the first endogenous molecules proven to be particularly adept in stimulating APCs to provide costimulation [73]. Studies have shown that the signals provided by the HSPs to the APCs do not occur through the traditional pattern recognition receptors which include the TLRs. Rather, recent studies have shown that the immunogenic HSPs utilize CD91 to transmit signals to the APC [71]. Primary APCs were shown to be activated by HSPs in a CD91-dependent manner suggesting that CD91 was acting as a signaling receptor for the immunogenic HSPs. The $\beta$ chain of CD91, which has two NPXY sequences that are consensus motifs for phosphorylation and signal transduction, was subsequently mutated. Upon tyrosine to phenylalanine mutation, CD91 failed to transmit intracellular signals in response to HSP stimulation, abrogating the costimulation provided by the APC. The signaling pathway(s) initiated by CD91 upon HSP stimulation involves the activation of NF$\kappa \mathrm{B}$ and p38 MAPK although other molecules are yet to be identified. Downstream of intracellular signaling, a number of cytokines are released by HSP-stimulated APCs including TNF- $\alpha$, IL-1 $\beta$, IL-6, IL-12, and GM-CSF [71]. Other studies have shown that, in addition to cytokine production by HSP-stimulated APCS, the APCs upregulate expression of costimulatory molecules and maturation markers including CD80, CD86, CD40, and MHC II [74]. The complete array of costimulatory molecules and cytokines is dependent on the type of APC (macrophage or DC subsets) that is stimulated and the HSP (hsp70, hsp90, calreticulin or gp96) that is used for stimulation (Table 2).

CD91 thus has a role in signal 1 (cross-presentation) and 2 (costimulation) that is provided by the APC to T cells in response to extracellular HSP. Similar to HSP-mediated cross-presentation of peptides, other receptors besides CD91 have been suggested to be signaling HSP receptors. However there is abundant published literature that the suggested TLR2/4 receptors were implicated because of the use of endotoxin-contaminated HSP preparations, especially from recombinant sources. A discussion of HSP receptors has been published elsewhere [25]. The flexibility in the pattern of costimulation triggered by various HSPs in a variety of experimental settings has implications in several fields of immunology and we focus here on a discussion on a role in autoimmune diseases.

\section{Extracellular HSPs and the Etiology of Autoimmunity}

As discussed above, APCs stimulated with various HSPs secrete proinflammatory cytokines such as IL-1 $\beta$, IL-6, and TNF- $\alpha$ among others (Table 2 ). In addition, HSPs chaperone self-peptides that can be cross-presented as efficiently as the antigenic peptides. The former of these events has the potential to trigger chronic inflammation during the continuous presence of HSPs in the extracellular environment. The two events concurrently can prime autoreactive $\mathrm{T}$ cells if such $\mathrm{T}$ cells are not thymically deleted. In at least one autoimmune disease, this concept is strongly supported. The etiology of rheumatoid arthritis remains largely unresolved; however, several factors that contribute to the initiation and/or progression of the disease can be pinpointed. The observation of elevated levels of hsp70 in synovial fluids from inflamed joints of RA patients is one of these factors. Hsp70 is found both within the fibroblasts at the joint and in the fluid itself $[99,100]$. The significant increase in extracellular hsp70 in arthritic joints is profoundly correlative because nonarthritic joints in the same individual patients have no elevation in hsp70. As mentioned above, hsp70 can interact with its cell surface receptor CD91, and potentially other receptors, on cells to induce the release of proinflammatory cytokines such as IL- $1 \beta$, IL- 6 , and TNF- $\alpha$. The observation of elevated hsp70 levels in synovial fluids from inflamed joints implicates hsp70 as an initiator of inflammation and/or a perpetrator of these events. In this disease hsp70 will chaperone self-peptides that can be cross-presented by local APCs [101]. Such cross-presentation of self-antigens appears to be sufficient to break tolerance and for priming selfantigen-specific $\mathrm{T}$ cells which could contribute to cellular destruction observed in arthritic joints.

\section{HSP Immunotherapy for Autoimmune Diseases}

Immunization of mice with HSPs typically elicits Th1 responses characterized by CTL specific for antigenic peptides chaperoning the HSP. Optimal immunizing doses range from 1 to $10 \mu \mathrm{g}$ at the intradermal or subcutaneous route. Upward titrations of this dose revealed a surprising and apparently paradoxical result. Doses of HSPs that were 10 times higher than the immunizing dose administered to mice were shown to prime an immunosuppressive phenotype characterized by expansion of $\mathrm{CD}^{+}$Tregs [60, 102-104]. The immunosuppressive response could also be transferred to naïve mice by transfer of the expanded $\mathrm{CD} 4^{+}$Treg cell population [103]. The phenotype is observed when there is a prior ongoing CTL response, and in at least one system, Tregs from high dose gp96-immunized mice significantly 


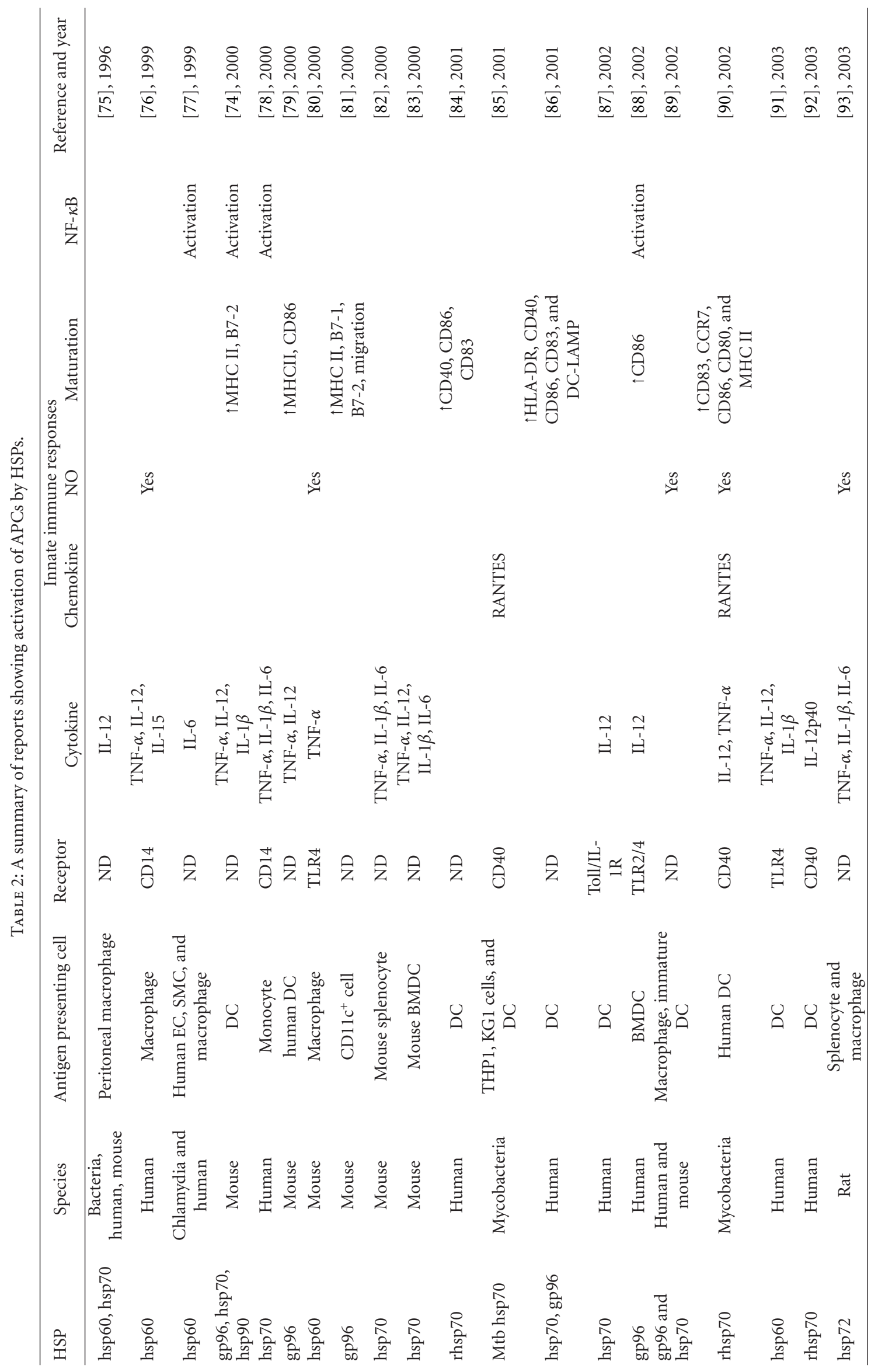




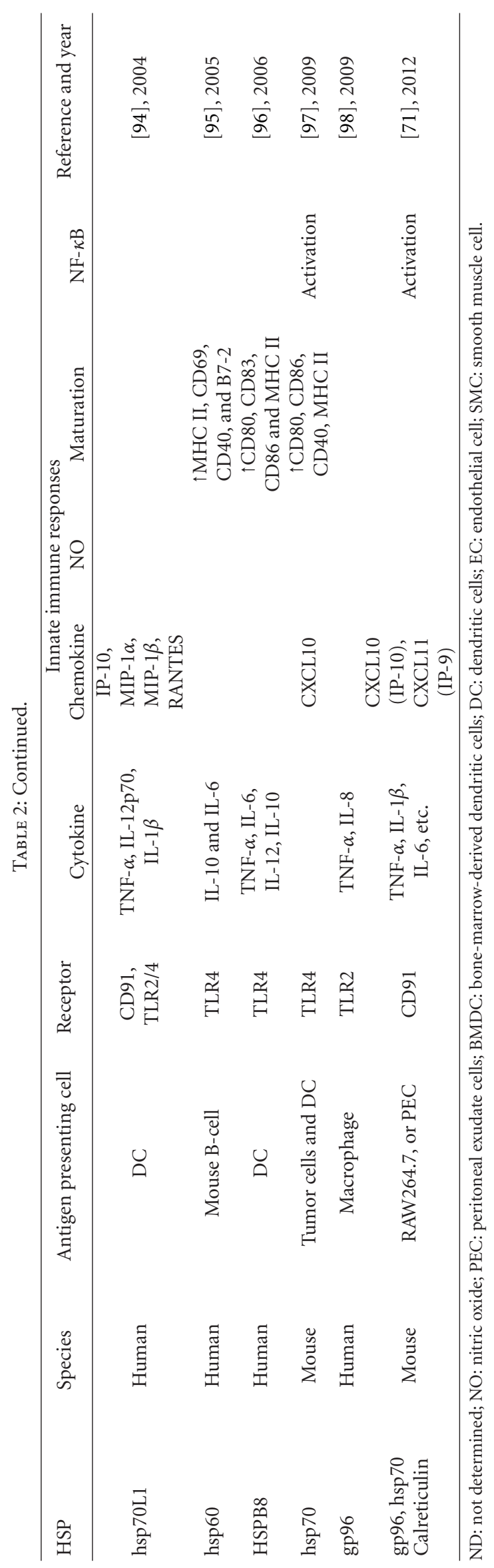


suppressed the IFN- $\gamma$ production by autologous $\mathrm{CD} 4^{+}$and CD8 ${ }^{+} \mathrm{T}$ cells [105].

The application of this "high dose" phenomenon has been tested in mouse models of autoimmunity including diabetes and experimental autoimmune encephalomyelitis [103]. In both models, administration of "high doses" of HSPs reduced the severity of disease or prevented its development outright. In the diabetic model, high doses of HSP were administered to NOD mice that were older than 4 months at which point $\beta$-islet-specific pathogenic $\mathrm{T}$ cells were already present in the pancreas. In the EAE model, high dose of HSP was administered after immunizing mice with the MOG peptide which primes pathogenic $\mathrm{CD}^{+} \mathrm{T}$ cells. The HSPs used in these studies did not chaperone any antigenic peptides related to the disease model and led to the conclusion that the ability to prime Treg cells was inherent to the HSP molecule itself. The less preferred explanation would be a common self-peptide associated with gp96 regardless of the source of HSP in a global disease setting. Our current understanding of the diversity of responses of APCs stimulated with HSPs (Table 2) sheds some light on the mechanism. It strongly suggests that the disparity of responses in immunization with high and low doses of HSP results from targeting different sets of APCs, possibly through CD91 and additional cell surface receptors, leading to a new repertoire of cytokines and/or costimulatory molecules. Higher doses of HSPs may target different subsets of APCs or stimulate multiple receptors in the same APCs (as the immunogenic dose) to elicit distinct costimulatory profiles [105]. The alternative costimulation could include TGF- $\beta$, PD-L1, and other Treg skewing molecules and would be predicted to be dominant over other signals. This area is under investigation and definition of these mechanisms will offer novel targets for inhibition in autoimmune diseases.

These data suggest a delicate balance between regulatory and effector T cells mediated by HSPs and is supported by the recent demonstration of significant enhancement of gp96-primed CTL activity after anti-CD25 treatment [106]. By blocking Treg generation, gp96 was able to mediate stronger peptide-specific CTL responses in $\mathrm{BALB} / \mathrm{c}$ mice and synergistically enhanced gp96 tumor vaccine-induced antitumor immunity.

\section{Conclusions}

Over the past 3 decades the various roles of HSPs in the immune systems have been explored and characterized. It appears that the evolutionarily ancient chaperone functions of HSPs in binding peptides and proteins have been commandeered by the relatively recent development of the adaptive immune system. However recent studies suggest that, parallel to evolution of innate responses, multicellular organisms are alerted to aberrant cellular damage by utilization of pre-existing receptors (CD91) to detect the presence of abundant intracellular molecules (HSPs). We draw many similarities between the innate immune responses elicited by PAMPs through PRRs and those by HSPs through CD91 in terms of costimulation for T-cell priming. Indeed the HSP-CD91 network has been well documented not only in mammals but also in amphibians. While CD91 is a wellstudied receptor for HSPs (Table 1), there may be other molecules that may serve as receptors, offering a diversity of responses that may be elicited by each HSP. Again, the diversity of PRRs for recognition of various PAMPs is well noted in innate immunity. The immune responses primed by extracellular HSPs are dictated by the costimulation that is elicited and is as diverse as the APC the HSP will encounter. The immune responses range from antitumor and pathogen immunity to suppressive responses, with the latter being applied to the therapy of autoimmune diseases. With greater understanding of the immunobiology of these proteins, we anticipate that vaccine design will be enhanced.

\section{References}

[1] S. Lindquist and E. A. Craig, "The heat-shock proteins," Annual Review of Genetics, vol. 22, pp. 631-677, 1988.

[2] R. J. Binder, "Heat-shock protein-based vaccines for cancer and infectious disease," Expert Review of Vaccines, vol. 7, no. 3, pp. 383-393, 2008.

[3] X. Y. Wang, L. Kazim, E. A. Repasky, and J. R. Subjeck, "Characterization of heat shock protein 110 and glucoseregulated protein 170 as cancer vaccines and the effect of fever-range hyperthermia on vaccine activity," Journal of Immunology, vol. 166, no. 1, pp. 490-497, 2001.

[4] M. H. Manjili, R. Henderson, X. Y. Wang et al., "Development of a recombinant HSP110-HER-2/neu vaccine using the chaperoning properties of HSP110," Cancer Research, vol. 62, no. 6, pp. 1737-1742, 2002.

[5] P. Cresswell, A. L. Ackerman, A. Giodini, D. R. Peaper, and P. A. Wearsch, "Mechanisms of MHC class I-restricted antigen processing and cross-presentation," Immunological Reviews, vol. 207, pp. 145-157, 2005.

[6] P. K. Srivastava, H. Udono, N. E. Blachere, and Z. Li, "Heat shock proteins transfer peptides during antigen processing and CTL priming," Immunogenetics, vol. 39, no. 2, pp. 93-98, 1994.

[7] R. J. Binder, N. E. Blachere, and P. K. Srivastava, "Heat shock protein-chaperoned peptides but not free peptides introduced into the cytosol are presented efficiently by major histocompatibility complex I molecules," Journal of Biological Chemistry, vol. 276, no. 20, pp. 17163-17171, 2001.

[8] J. Kunisawa and N. Shastri, "Hsp90 $\alpha$ chaperones large Cterminally extended proteolytic intermediates in the MHC class I antigen processing pathway," Immunity, vol. 24, no. 5, pp. 523-534, 2006.

[9] M. K. Callahan, M. Garg, and P. K. Srivastava, "Heat-shock protein 90 associates with $\mathrm{N}$-terminal extended peptides and is required for direct and indirect antigen presentation," Proceedings of the National Academy of Sciences of the United States of America, vol. 105, no. 5, pp. 1662-1667, 2008.

[10] M. S. Villanueva, P. Fischer, K. Feen, and E. G. Pamer, "Efficiency of MHC class I antigen processing: a quantitative analysis," Immunity, vol. 1, no. 6, pp. 479-489, 1994.

[11] J. W. Yewdell, E. Reits, and J. Neefjes, "Making sense of mass destruction: quantitating MHC class I antigen presentation," Nature Reviews Immunology, vol. 3, no. 12, pp. 952-961, 2003.

[12] A. Ménoret, P. Peng, and P. K. Srivastava, "Association of peptides with heat shock protein gp96 occurs in vivo and not after cell lysis," Biochemical and Biophysical Research Communications, vol. 262, no. 3, pp. 813-818, 1999. 
[13] P. Peng, A. Ménoret, and P. K. Srivastava, "Purification of immunogenic heat shock protein 70-peptide complexes by ADP-affinity chromatography," Journal of Immunological Methods, vol. 204, no. 1, pp. 13-21, 1997.

[14] T. P. Dick, T. Ruppert, M. Groettrup et al., "Coordinated dual cleavages induced by the proteasome regulator PA28 lead to dominant MHC ligands," Cell, vol. 86, no. 2, pp. 253-262, 1996.

[15] T. Ishii, H. Udono, T. Yamano et al., "Isolation of MHC class I-restricted tumor antigen peptide and its precursors associated with heat shock proteins hsp70, hsp90, and gp96," Journal of Immunology, vol. 162, no. 3, pp. 1303-1309, 1999.

[16] P. Stocki, N. J. Morris, C. Preisinger et al., "Identification of potential HLA class i and class II epitope precursors associated with heat shock protein 70 (HSPA)," Cell Stress and Chaperones, vol. 15, no. 5, pp. 729-741, 2010.

[17] L. E. Kropp, M. Garg, and R. J. Binder, "Ovalbuminderived precursor peptides are transferred sequentially from gp96 and calreticulin to MHC class I in the endoplasmic reticulum," Journal of Immunology, vol. 184, no. 10, pp. 56195627, 2010.

[18] T. J. F. Nieland, M. C. A. A. Tan, M. M. V. Muijen, F. Koning, A. M. Kruisbeek, and G. M. Van Bleek, "Isolation of an immunodominant viral peptide that is endogenously bound to the stress protein GP96/GRP94," Proceedings of the National Academy of Sciences of the United States of America, vol. 93, no. 12, pp. 6135-6139, 1996.

[19] M. Breloer, T. Marti, B. Fleischer, and A. von Bonin, "1998Isolation of processed, H-2Kb-binding ovalbuminderived peptides associated with the stress proteins HSP70 and gp96," European Journal of Immunology, vol. 28, pp. 1016-1021, 1998.

[20] D. Arnold, C. Wahl, S. Faath, H. G. Rammensee, and H. Schild, "Influences of transporter associated with antigen processing (TAP) on the repertoire of peptides associated with the endoplasmic reticulum- resident stress protein gp96," Journal of Experimental Medicine, vol. 186, no. 3, pp. 461-466, 1997.

[21] M. Li, G. M. Davey, R. M. Sutherland et al., "Cell-associated ovalbumin is cross-presented much more efficiently than soluble ovalbumin in vivo," Journal of Immunology, vol. 166, no. 10, pp. 6099-6103, 2001.

[22] R. J. Binder and P. K. Srivastava, "Peptides chaperoned by heat-shock proteins are a necessary and sufficient source of antigen in the cross-priming of $\mathrm{CD}^{+} \mathrm{T}$ cells," Nature Immunology, vol. 6, no. 6, pp. 593-599, 2005.

[23] R. J. Binder, D. K. Han, and P. K. Srivastava, "CD91: a receptor for heat shock protein gp96," Nature Immunology, vol. 1, no. 2, pp. 151-155, 2000.

[24] S. Basu, R. J. Binder, T. Ramalingam, and P. K. Srivastava, "CD91 is a common receptor for heat shock proteins gp96, hsp90, hsp70, and calreticulin," Immunity, vol. 14, no. 3, pp. 303-313, 2001.

[25] R. J. Binder, "Hsp receptors: the cases of identity and mistaken identity," Current Opinion in Molecular Therapeutics, vol. 11, no. 1, pp. 62-71, 2009.

[26] D. Arnold-Schild, D. Hanau, D. Spehner et al., "Cutting edge: receptor-mediated endocytosis of heat shock proteins by professional antigen-presenting cells," Journal of Immunology, vol. 162, no. 7, pp. 3757-3760, 1999.

[27] H. Singh-Jasuja, R. E. M. Toes, P. Spee et al., "Crosspresentation of glycoprotein 96-associated antigens: on major histocompatibility complex class I molecules requires receptor-mediated endocytosis," Journal of Experimental Medicine, vol. 191, no. 11, pp. 1965-1974, 2000.

[28] D. Lipsker, U. Ziylan, D. Spehner et al., "Heat shock proteins 70 and 60 share common receptors which are expressed on human monocyte-derived but not epidermal dendritic cells," European Journal of Immunology, vol. 32, pp. 322-332, 2002.

[29] B. Berwin, M. F. N. Rosser, G. Brinker, and C. V. Nicchitta, "Transfer of GRP94(Gp96)-associated peptides onto endosomal MHC class I molecules," Traffic, vol. 3, no. 5, pp. 358366, 2002.

[30] T. Kurotaki, Y. Tamura, G. Ueda et al., "Efficient crosspresentation by heat shock protein 90-peptide complexloaded dendritic cells via an endosomal pathway," Journal of Immunology, vol. 179, no. 3, pp. 1803-1813, 2007.

[31] F. Castellino, P. E. Boucher, K. Eichelberg et al., "Receptormediated uptake of antigen/heat shock protein complexes results in major histocompatibility complex class I antigen presentation via two distinct processing pathways," Journal of Experimental Medicine, vol. 191, no. 11, pp. 1957-1964, 2000.

[32] T. Ichiyanagi, T. Imai, C. Kajiwara et al., "Essential role of endogenous heat shock protein 90 of dendritic cells in antigen cross-presentation," Journal of Immunology, vol. 185, no. 5, pp. 2693-2700, 2010.

[33] J. Oura, Y. Tamura, K. Kamiguchi et al., "Extracellular heat shock protein 90 plays a role in translocating chaperoned antigen from endosome to proteasome for generating antigenic peptide to be cross-presented by dendritic cells," International Immunology, vol. 23, no. 4, pp. 223-237, 2011.

[34] A. D. H. Doody, J. T. Kovalchin, M. A. Mihalyo, A. T. Hagymasi, C. G. Drake, and A. J. Adler, "Glycoprotein 96 can chaperone both MHC class I- and class II-restricted epitopes for in vivo presentation, but selectively primes $\mathrm{CD} 8^{+} \mathrm{T}$ cell effector function," Journal of Immunology, vol. 172, no. 10, pp. 6087-6092, 2004.

[35] D. SenGupta, P. J. Norris, T. J. Suscovich et al., "Heat shock protein-mediated cross-presentation of exogenous HIV antigen on HLA class I and class II," Journal of Immunology, vol. 173, no. 3, pp. 1987-1993, 2004.

[36] A. A. R. Tobian, D. H. Canaday, and C. V. Harding, "Bacterial heat shock proteins enhance class II MHC antigen processing and presentation of chaperoned peptides to $\mathrm{CD} 4^{+} \mathrm{T}$ cells," Journal of Immunology, vol. 173, no. 8, pp. 5130-5137, 2004.

[37] T. Matsutake, T. Sawamura, and P. K. Srivastava, "High efficiency CD91- and LOX-1-mediated re-presentation of gp96-chaperoned peptides by MHC II molecules," Cancer Immunity, vol. 10, p. 7, 2010.

[38] K. McLaughlin, J. Seago, L. Robinson, C. Kelly, and B. Charleston, "Hsp70 enhances presentation of FMDV antigen to bovine $\mathrm{CD} 4^{+} \mathrm{T}$ cells in vitro," Veterinary Research, vol. 41 , no. 3, p. 36, 2010.

[39] H. Bendz, S. C. Ruhland, M. J. Pandya et al., "Human heat shock protein 70 enhances tumor antigen presentation through complex formation and intracellular antigen delivery without innate immune signaling," Journal of Biological Chemistry, vol. 282, no. 43, pp. 31688-31702, 2007.

[40] Y. Huang, C. Biswas, D. A. Klos Dehring et al., "The actin regulatory protein HS1 is required for antigen uptake and presentation by dendritic cells," The Journal of Immunology, vol. 187, pp. 5952-5963, 2011.

[41] S. Zitzler, A. Hellwig, F. U. Hartl, F. Wieland, and P. Diestelkötter-Bachert, "Distinct binding sites for the ATPase and substrate-binding domain of human Hsp70 on the cell 
surface of antigen presenting cells," Molecular Immunology, vol. 45, no. 15, pp. 3974-3983, 2008.

[42] E. Noessner, R. Gastpar, V. Milani et al., “Tumor-derived heat shock protein 70 peptide complexes are cross-presented by human dendritic cells," Journal of Immunology, vol. 169, no. 10, pp. 5424-5432, 2002.

[43] A. A. R. Tobian, D. H. Canaday, W. H. Boom, and C. V. Harding, "Bacterial heat shock proteins promote CD91dependent class I MHC cross-presentation of chaperoned peptide to $\mathrm{CD} 8^{+} \mathrm{T}$ cells by cytosolic mechanisms in dendritic cells versus vacuolar mechanisms in macrophages," Journal of Immunology, vol. 172, no. 9, pp. 5277-5286, 2004.

[44] R. J. Binder and P. K. Srivastava, "Essential role of CD91 in re-presentation of gp96-chaperoned peptides," Proceedings of the National Academy of Sciences of the United States of America, vol. 101, no. 16, pp. 6128-6133, 2004.

[45] J. Robert, T. Ramanayake, G. D. Maniero, H. Morales, and A. S. Chida, "Phylogenetic conservation of glycoprotein 96 ability to interact with CD91 and facilitate antigen crosspresentation," Journal of Immunology, vol. 180, no. 5, pp. 3176-3182, 2008.

[46] S. Tischer, M. Basila, B. Maecker-Kolhoff et al., "Heat shock protein 70/peptide complexes: potent mediators for the generation of antiviral T cells particularly with regard to low precursor frequencies," Journal of Translational Medicine, vol. 9, p. 175, 2011.

[47] N. Fischer, M. Haug, W. W. Kwok et al., "Involvement of CD91 and scavenger receptors in Hsp70-facilitated activation of human antigen-specific $\mathrm{CD} 4^{+}$memory T cells," European Journal of Immunology, vol. 40, no. 4, pp. 986-997, 2010.

[48] M. F. M. Langelaar, J. C. Hope, V. P. M. G. Rutten, J. P. T. M. Noordhuizen, W. Van Eden, and A. P. Koets, "Mycobacterium avium ssp. paratuberculosis recombinant heat shock protein 70 interaction with different bovine antigen-presenting cells," Scandinavian Journal of Immunology, vol. 61, no. 3, pp. 242250, 2005.

[49] B. Berwin, J. P. Hart, S. V. Pizzo, and C. V. Nicchitta, "Cutting edge: CD91-independent cross-presentation of GRP94(gp96)-associated peptides," Journal of Immunology, vol. 168, no. 9, pp. 4282-4286, 2002.

[50] A. R. Jockheck-Clark, E. V. Bowers, M. B. Totonchy, J. Neubauer, S. V. Pizzo, and C. V. Nicchitta, "Re-examination of CD91 function in GRP94 (glycoprotein 96) surface binding, uptake, and peptide cross-presentation," Journal of Immunology, vol. 185, no. 11, pp. 6819-6830, 2010.

[51] A. Murshid, J. Gong, and S. K. Calderwood, "Heat shock protein 90 mediates efficient antigen cross presentation through the scavenger receptor expressed by endothelial cells-I," Journal of Immunology, vol. 185, no. 5, pp. 29032917, 2010.

[52] J. J. Walters and B. Berwin, "Differential CD91 dependence for calreticulin and Pseudomonas exotoxin-A endocytosis," Traffic, vol. 6, no. 12, pp. 1173-1182, 2005.

[53] B. Berwin, Y. Delneste, R. V. Lovingood, S. R. Post, and S. V. Pizzo, "SREC-I, a type F scavenger receptor, is an endocytic receptor for calreticulin," Journal of Biological Chemistry, vol. 279, no. 49, pp. 51250-51257, 2004.

[54] Y. Delneste, G. Magistrelli, J. F. Gauchat et al., "Involvement of LOX-1 in dendritic cell-mediated antigen crosspresentation," Immunity, vol. 17, no. 3, pp. 353-362, 2002.

[55] B. Berwin, J. P. Hart, S. Rice et al., "Scavenger receptorA mediates gp96/GRP94 and calreticulin internalization by antigen-presenting cells," The EMBO Journal, vol. 22, no. 22, pp. 6127-6136, 2003.

[56] E. F. Tewalt, J. C. Maynard, J. J. Walters et al., "Redundancy renders the glycoprotein 96 receptor scavenger receptor A dispensable for cross priming in vivo," Immunology, vol. 125, no. 4, pp. 480-491, 2008.

[57] J. G. Facciponte, X. Y. Wang, and J. R. Subjeck, "Hsp110 and Grp170, members of the Hsp70 superfamily, bind to scavenger receptor-A and scavenger receptor expressed by endothelial cell-I," European Journal of Immunology, vol. 37, no. 8, pp. 2268-2279, 2007.

[58] J. J. Wassenberg, C. Dezfulian, and C. V. Nicchitta, "Receptor mediated and fluid phase pathways for internalization of the ER Hsp90 chaperone GRP94 in murine macrophages," Journal of Cell Science, vol. 112, no. 13, pp. 2167-2175, 1999.

[59] Z. Li and P. K. Srivastava, "Tumor rejection antigen gp96/grp94 is an ATPase: implications for protein folding and antigen presentation," The EMBO Journal, vol. 12, no. 8, pp. 3143-3151, 1993.

[60] P. K. Srivastava, A. B. DeLeo, and L. J. Old, "Tumor rejection antigens of chemically induced sarcomas of inbred mice," Proceedings of the National Academy of Sciences of the United States of America, vol. 83, no. 10, pp. 3407-3411, 1986.

[61] R. J. Binder, J. B. Kelly, R. E. Vatner, and P. K. Srivastava, "Specific immunogenicity of heat shock protein gp96 derives from chaperoned antigenic peptides and not from contaminating proteins," Journal of Immunology, vol. 179, no. 11, pp. 7254-7261, 2007.

[62] H. Udono and P. K. Srivastava, "Comparison of tumorspecific immunogenicities of stress-induced proteins gp96, hsp90, and hsp70," Journal of Immunology, vol. 152, no. 11, pp. 5398-5403, 1994.

[63] H. Udono, D. L. Levey, and P. K. Srivastava, "Cellular requirements for tumor-specific immunity elicited by heat shock proteins: tumor rejection antigen gp96 primes $\mathrm{CD}^{+} \mathrm{T}$ cells in vivo," Proceedings of the National Academy of Sciences of the United States of America, vol. 91, no. 8, pp. 3077-3081, 1994.

[64] S. Nair, P. A. Wearsch, D. A. Mitchell, J. J. Wassenberg, E. Gilboa, and C. V. Nicchitta, "Calreticulin displays in vivo peptide-binding activity and can elicit CTL responses against bound peptides," Journal of Immunology, vol. 162, no. 11, pp. 6426-6432, 1999.

[65] S. Basu and P. K. Srivastava, "Calreticulin, a peptide-binding chaperone of the endoplasmic reticulum, elicits tumorand peptide-specific immunity," Journal of Experimental Medicine, vol. 189, no. 5, pp. 797-802, 1999.

[66] D. Arnold, S. Faath, H. G. Rammensee, and H. Schild, "Cross-priming of minor histocompatibility antigen-specific cytotoxic $\mathrm{T}$ cells upon immunization with the heat shock protein gp96," Journal of Experimental Medicine, vol. 182, no. 3, pp. 885-889, 1995.

[67] N. E. Blachere, Z. Li, R. Y. Chandawarkar et al., "Heat shock protein-peptide complexes, reconstituted in vitro, elicit peptide-specific cytotoxic T lymphocyte response and tumor immunity," Journal of Experimental Medicine, vol. 186, no. 8, pp. 1315-1322, 1997.

[68] H. Udono, T. Yamano, Y. Kawabata, M. Ueda, and K. Yui, "Generation of cytotoxic T lymphocytes by MHC class I ligands fused to heat shock cognate protein 70," International Immunology, vol. 13, no. 10, pp. 1233-1242, 2001.

[69] M. Navaratnam, M. S. Deshpande, M. J. Hariharan, D. S. Zatechka, and S. Srikumaran, "Heat shock protein-peptide 
complexes elicit cytotoxic T-lymphocyte and antibody responses specific for bovine herpesvirus 1," Vaccine, vol. 19, no. 11-12, pp. 1425-1434, 2001.

[70] J. Jimbo, K. Sato, T. Hosoki et al., "Induction of leukemiaspecific antibodies by immunotherapy with leukemia-cellderived heat shock protein 70," Cancer Science, vol. 99, no. 7, pp. 1427-1434, 2008.

[71] S. Pawaria and R. J. Binder, "CD91-dependent programming of T-helper cell responses following heat shock protein immunization,” Nature Communications, vol. 2, p. 521, 2011.

[72] X. Gong, W. Gai, J. Xu, W. Zhou, and P. Tien, "Glycoprotein 96-mediated presentation of human immunodeficiency virus type 1 (HIV-1)-specific human leukocyte antigen class Irestricted peptide and humoral immune responses to HIV-1 p24," Clinical and Vaccine Immunology, vol. 16, no. 11, pp. 1595-1600, 2009.

[73] P. Srivastava, "Interaction of heat shock proteins with peptides and antigen presenting cells: chaperoning of the innate and adaptive immune responses," Annual Review of Immunology, vol. 20, pp. 395-425, 2002.

[74] S. Basu, R. J. Binder, R. Suto, K. M. Anderson, and P. K. Srivastava, "Necrotic but not apoptotic cell death releases heat shock proteins, which deliver a partial maturation signal to dendritic cells and activate the NF- $\kappa$ B pathway," International Immunology, vol. 12, no. 11, pp. 1539-1546, 2000.

[75] M. J. Skeen, M. A. Miller, T. M. Shinnick, and H. Kirk Ziegler, "Regulation of murine macrophage IL-12 production: activation of macrophages in vivo, restimulation in vitro, and modulation by other cytokines," Journal of Immunology, vol. 156, no. 3, pp. 1196-1206, 1996.

[76] W. Chen, U. Syldath, K. Bellmann, V. Burkart, and H. Kolb, "Human $60-\mathrm{kDa}$ heat-shock protein: a danger signal to the innate immune system," Journal of Immunology, vol. 162, no. 6, pp. 3212-3219, 1999.

[77] A. Kol, T. Bourcier, A. H. Lichtman, and P. Libby, "Chlamydial and human heat shock protein 60 s activate human vascular endothelium, smooth muscle cells, and macrophages," Journal of Clinical Investigation, vol. 103, no. 4, pp. 571-577, 1999.

[78] A. Asea, S. K. Kraeft, E. A. Kurt-Jones et al., "HSP70 stimulates cytokine production through a CD 14-dependant pathway, demonstrating its dual role as a chaperone and cytokine," Nature Medicine, vol. 6, no. 4, pp. 435-442, 2000.

[79] H. Singh-Jasuja, H. U. Scherer, N. Hilf et al., "The heat shock protein gp96 induces maturation of dendritic cells and down-regulation of its receptor," European Journal of Immunology, vol. 30, pp. 2211-2215, 2000.

[80] K. Ohashi, V. Burkart, S. Flohé, and H. Kolb, "Cutting edge: heat shock protein 60 is a putative endogenous ligand of the toll-like receptor-4 complex," Journal of Immunology, vol. 164, no. 2, pp. 558-561, 2000.

[81] R. J. Binder, K. M. Anderson, S. Basu, and P. K. Srivastava, "Cutting edge: heat shock protein gp96 induces maturation and migration of CD11 $\mathrm{c}^{+}$cells in vivo," Journal of Immunology, vol. 165, no. 11, pp. 6029-6035, 2000.

[82] A. Asea, E. Kabingu, M. A. Stevenson, and S. K. Calderwood, "HSP70 peptide-bearing and peptide-negative preparations act as chaperokines," Cell Stress Chaperones, vol. 5, pp. 425431, 2000.

[83] Y. Moroi, M. Mayhew, J. Trcka et al., "Induction of cellular immunity by immunization with novel hybrid peptides complexed to heat shock protein 70," Proceedings of the
National Academy of Sciences of the United States of America, vol. 97, no. 7, pp. 3485-3490, 2000.

[84] M. C. Kuppner, R. Gastpar, S. Gelwer et al., "The role of heat shock protein (hsp70) in dendritic cell maturation: Hsp70 induces the maturation of immature dendritic cells but reduces DC differentiation from monocyte precursors," European Journal of Immunology, vol. 31, pp. 1602-1609, 2001.

[85] Y. Wang, C. G. Kelly, J. T. Karttunen et al., "Cd40 is a cellular receptor mediating mycobacterial heat shock protein 70 stimulation of CC-chemokines," Immunity, vol. 15, no. 6, pp. 971-983, 2001.

[86] S. Somersan, M. Larsson, J. F. Fonteneau, S. Basu, P. Srivastava, and N. Bhardwaj, "Primary tumor tissue lysates are enriched in heat shock proteins and induce the maturation of human dendritic cells," Journal of Immunology, vol. 167, no. 9, pp. 4844-4852, 2001.

[87] R. M. Vabulas, P. Ahmad-Nejad, S. Ghose, C. J. Kirschning, R. D. Issels, and H. Wagner, "HSP70 as endogenous stimulus of the toll/interleukin-1 receptor signal pathway," Journal of Biological Chemistry, vol. 277, no. 17, pp. 15107-15112, 2002.

[88] R. M. Vabulas, S. Braedel, N. Hilf et al., "The endoplasmic reticulum-resident heat shock protein Gp96 activates dendritic cells via the toll-like receptor 2/4 pathway," Journal of Biological Chemistry, vol. 277, no. 23, pp. 20847-20853, 2002.

[89] N. N. Panjwani, L. Popova, and P. K. Srivastava, "Heat shock proteins gp96 and hsp70 activate the release of nitric oxide by APCs," Journal of Immunology, vol. 168, no. 6, pp. 2997-3003, 2002.

[90] Y. Wang, C. G. Kelly, M. Singh et al., "Stimulation of Th1-polarizing cytokines, C-C chemokines, maturation of dendritic cells, and adjuvant function by the peptide binding fragment of heat shock protein 70," Journal of Immunology, vol. 169, no. 5, pp. 2422-2429, 2002.

[91] S. B. Flohé, J. Brüggemann, S. Lendemans et al., "Human heat shock protein 60 induces maturation of dendritic cells versus a Th1-promoting phenotype," Journal of Immunology, vol. 170, no. 5, pp. 2340-2348, 2003.

[92] D. G. Millar, K. M. Garza, B. Odermatt et al., "Hsp70 promotes antigen-presenting cell function and converts Tcell tolerance to autoimmunity in vivo," Nature Medicine, vol. 9, no. 12, pp. 1469-1476, 2003.

[93] J. Campisi, T. H. Leem, and M. Fleshner, "Stress-induced extracellular Hsp72 is a functionally significant danger signal to the immune system," Cell Stress Chaperones, vol. 8, pp. 272-286, 2003.

[94] T. Wan, X. Zhou, G. Chen et al., "Novel heat shock protein Hsp70L1 activates dendritic cells and acts as a Th1 polarizing adjuvant," Blood, vol. 103, no. 5, pp. 1747-1754, 2004.

[95] M. Cohen-Sfady, G. Nussbaum, M. Pevsner-Fischer et al., "Heat shock protein 60 activates B cells via the TLR4-MyD88 pathway," Journal of Immunology, vol. 175, no. 6, pp. 35943602, 2005.

[96] M. F. Roelofs, W. C. Boelens, L. A. B. Joosten et al., "Identification of small heat shock protein B8 (HSP22) as a novel TLR4 ligand and potential involvement in the pathogenesis of rheumatoid arthritis," Journal of Immunology, vol. 176, no. 11, pp. 7021-7027, 2006.

[97] T. Chen, J. Guo, C. Han, M. Yang, and X. Cao, "Heat shock protein 70 , released from heat-stressed tumor cells, initiates antitumor immunity by inducing tumor cell chemokine production and activating dendritic cells via TLR4 pathway," Journal of Immunology, vol. 182, no. 3, pp. 1449-1459, 2009. 
[98] Q. Q. Huang, R. Sobkoviak, A. R. Jockheck-Clark et al., "Heat shock protein 96 is elevated in rheumatoid arthritis and activates macrophages primarily via TLR2 signaling," Journal of Immunology, vol. 182, no. 8, pp. 4965-4973, 2009.

[99] C. A. Martin, S. E. Carsons, R. Kowalewski, D. Bernstein, M. Valentino, and F. Santiago-Schwarz, "Aberrant extracellular and dendritic Cell (DC) surface expression of heat shock protein (hsp)70 in the rheumatoid joint: possible mechanisms of hsp/DC-mediated cross-priming," Journal of Immunology, vol. 171, no. 11, pp. 5736-5742, 2003.

[100] L. Sedlackova, T. T. H. Nguyen, D. Zlacka, A. Sosna, and I. Hromadnikova, "Cell surface and relative mRNA expression of heat shock protein 70 in human synovial cells," Autoimmunity, vol. 42, no. 1, pp. 17-24, 2009.

[101] I. Auger, J. M. Escola, J. P. Gorvel, and J. Roudier, "HLADR4 and HLA-DR10 motifs that carry susceptibility to rheumatoid arthritis bind $70-\mathrm{kD}$ heat shock proteins," Nature Medicine, vol. 2, no. 3, pp. 306-310, 1996.

[102] R. Y. Chandawarkar, M. S. Wagh, and P. K. Srivastava, "The dual nature of specific immunological activity of tumor-derived gp96 preparations," Journal of Experimental Medicine, vol. 189, no. 9, pp. 1437-1442, 1999.

[103] R. Y. Chandawarkar, M. S. Wagh, J. T. Kovalchin, and P. Srivastava, "Immune modulation with high-dose heat-schock protein gp96: therapy of murine autoimmune diabetes and encephalomyelitis," International Immunology, vol. 16, no. 4, pp. 615-624, 2004.

[104] J. T. Kovalchin, C. Mendonca, M. S. Wagh, R. Wang, and R. Y. Chandawarkar, "In vivo treatment of mice with heat shock protein, gp96, improves survival of skin grafts with minor and major antigenic disparity," Transplant Immunology, vol. 15, no. 3, pp. 179-185, 2006.

[105] Z. Liu, X. Li, L. Qiu et al., "Treg suppress CTL responses upon immunization with HSP gp96," European Journal of Immunology, vol. 39, no. 11, pp. 3110-3120, 2009.

[106] X. Yan, X. Zhang, Y. Wang et al., "Regulatory T-cell depletion synergizes with gp96-mediated cellular responses and antitumor activity," Cancer Immunology, Immunotherapy, vol. 60, no. 12, pp. 1763-1774, 2011. 


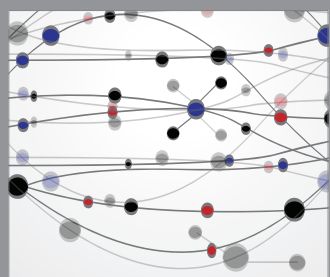

The Scientific World Journal
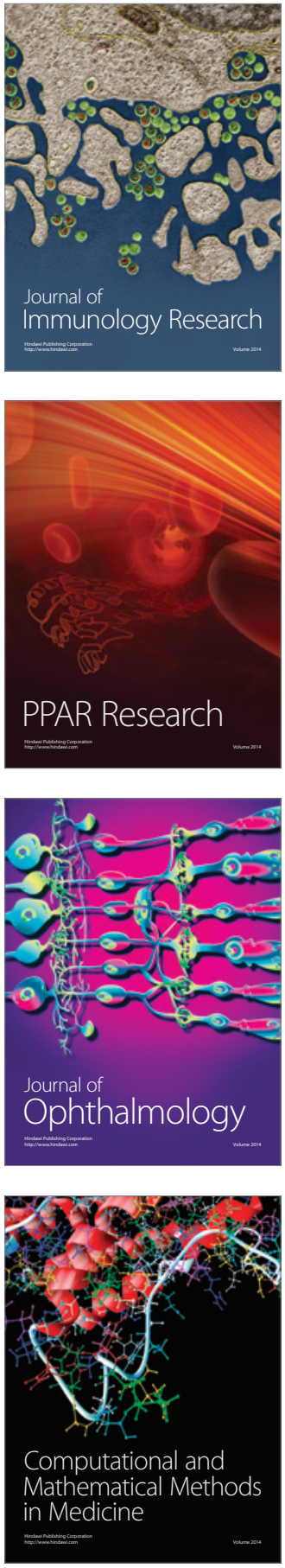

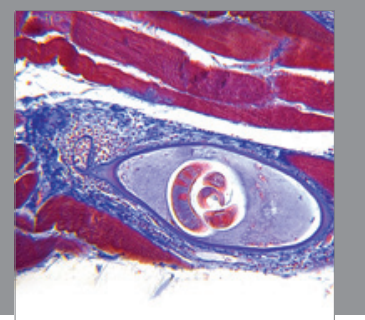

Gastroenterology

Research and Practice
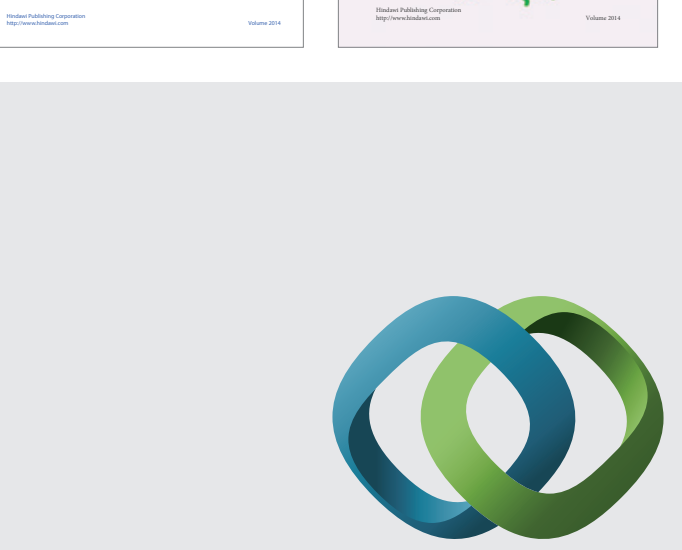

\section{Hindawi}

Submit your manuscripts at

http://www.hindawi.com
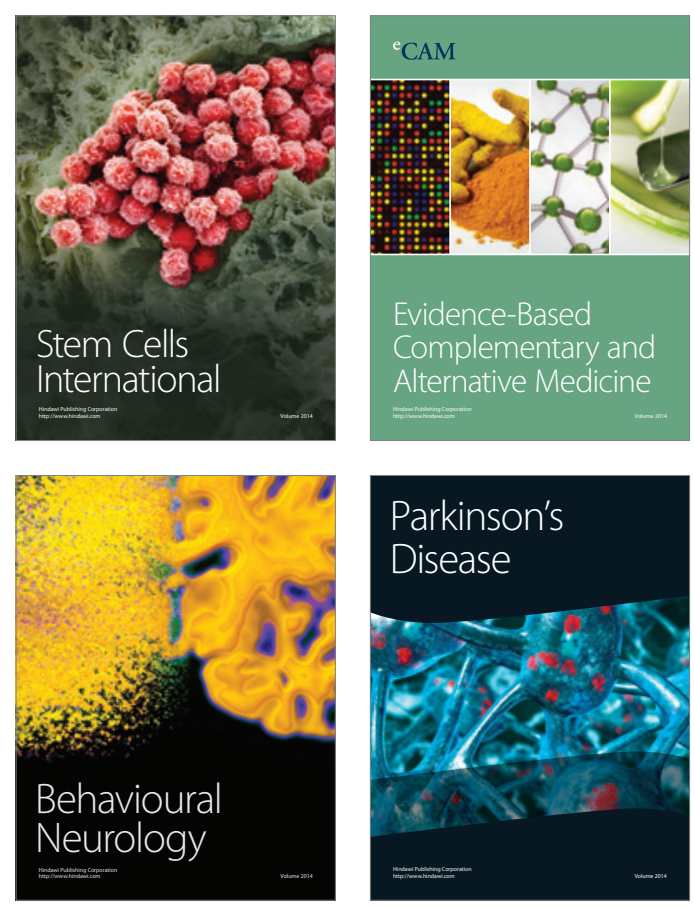

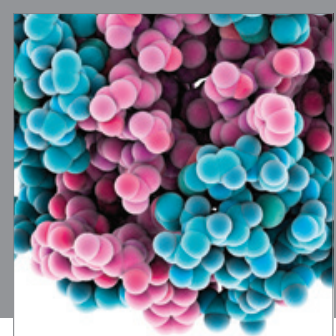

Journal of
Diabetes Research

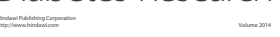

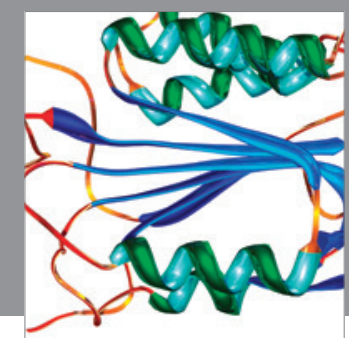

Disease Markers
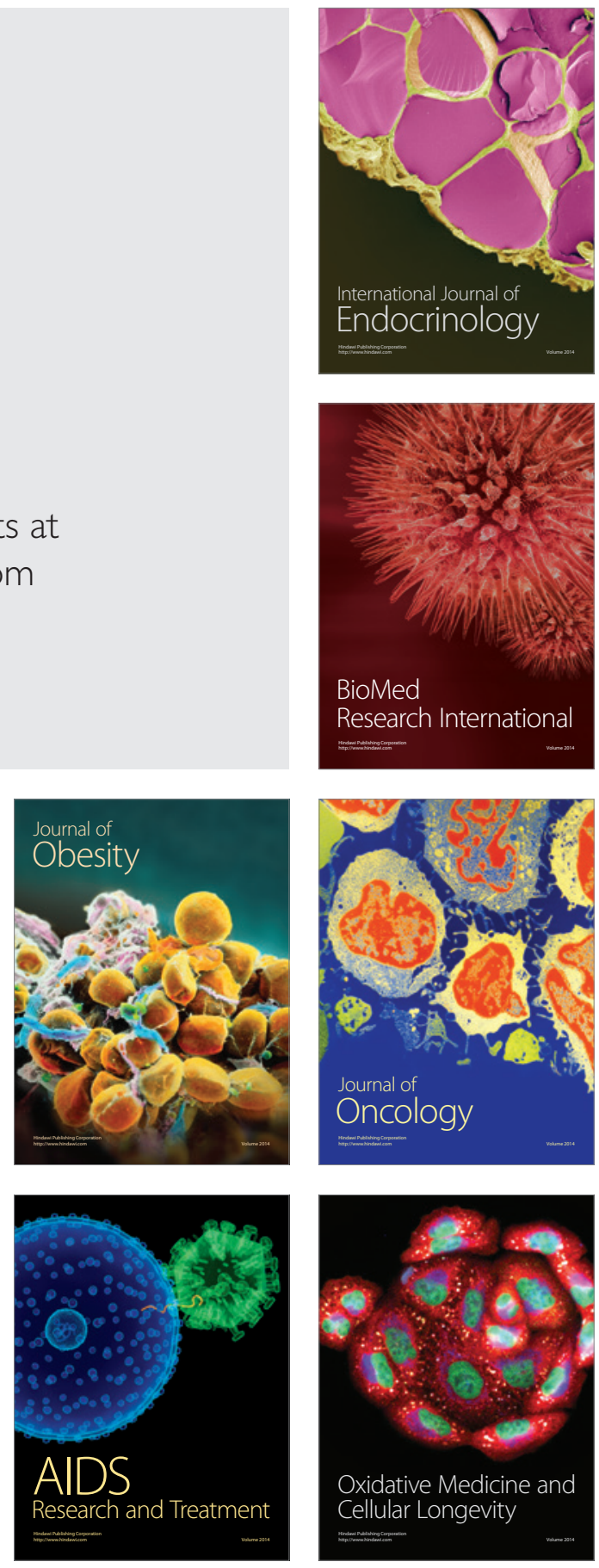